\title{
BMJ Open Blood pressure-lowering medicines implemented in 12 African countries: the cross-sectional multination EIGHT study
}

\author{
Pauline Cavagna (D) ,,2 Jean Laurent Takombe, ${ }^{3}$ Jean Marie Damorou, ${ }^{4}$ \\ Charles Kouam Kouam, ${ }^{5}$ Ibrahima Bara Diop, ${ }^{6}$ Stephane Méo lkama, ${ }^{7}$ \\ Kouadio Euloge Kramoh, ${ }^{8}$ Ibrahim Ali Toure, ${ }^{9}$ Dadhi Balde, ${ }^{10}$ Anastase Dzudie (D) ${ }^{11}$ \\ Beatriz Ferreira, ${ }^{12}$ Martin Houenassi, ${ }^{13}$ Adama Kane, ${ }^{14}$ Suzy Gisele Kimbally-kaki, ${ }^{7}$ \\ Samuel Kingue, ${ }^{15}$ Emmanuel Limbole, ${ }^{16,17}$ Liliane Mfeukeu Kuate, ${ }^{18}$ \\ Jean Bruno Mipinda, ${ }^{19}$ Roland N'Guetta, ${ }^{8}$ Carol Nhavoto, ${ }^{12}$ Abdallahi Sidy Ali, ${ }^{20}$ \\ Bamba Gaye (D) ,2 Gabriel S Tajeu, ${ }^{21}$ Diane Macquart De Terline, ${ }^{1,2}$ \\ Marie Cécile Perier, ${ }^{2}$ Michel Azizi, ${ }^{22,23,24}$ Xavier Jouven, ${ }^{2,24,25}$ Marie Antignac ${ }^{1,2}$
}

To cite: Cavagna $P$, Takombe JL, Damorou JM, et al. Blood pressure-lowering medicines implemented in 12 African countries: the cross-sectional multination EIGHT study. BMJ Open 2021;11:e049632. doi:10.1136/ bmjopen-2021-049632

- Prepublication history and additional supplemental material for this paper are available online. To view these files, please visit the journal online (http://dx.doi.org/10.1136/ bmjopen-2021-049632).

Received 30 January 2021 Accepted 01 October 2021

Check for updates

(c) Author(s) (or their employer(s)) 2021. Re-use permitted under CC BY-NC. No commercial re-use. See rights and permissions. Published by BMJ.

For numbered affiliations see end of article.

Correspondence to Dr Pauline Cavagna; pauline.cavagna@aphp.fr

\section{ABSTRACT}

Objective In Africa, the number of patients with hypertension is expected to reach 216.8 million by 2030 . Large-scale data on antihypertensive medications used in Sub-Saharan Africa (SSA) are scarce.

Here, we describe antihypertensive drug strategies and identify treatment factors associated with blood pressure (BP) control in 12 Sub-Saharan countries.

Setting Outpatient consultations for hypertension in urban tertiary cardiology centres of 29 hospitals from 17 cities across 12 SSA countries between January 2014 and November 2015.

Participants Patients $\geq 18$ years of age with hypertension were enrolled at any visit during outpatient consultations in the cardiology departments

Main outcome measure We collected BP levels, demographic characteristics and antihypertensive treatment use (including traditional medicine) of patients with hypertension attending outpatient visits. BP control was defined as seated office BP $<140 / 90 \mathrm{~mm} \mathrm{Hg}$. We used logistic regression with a random effect on countries to assess factors of BP control.

Results Overall, 2198 hypertensive patients were included and a total of $96.6 \%(n=2123)$ were on antihypertensive medications. Among treated patients, $653(30.8 \%)$ patients received a monotherapy by calcium channel blocker $(n=324,49.6 \%)$, renin-angiotensin system blocker (RAS) $(n=126,19.3 \%)$ or diuretic $(n=122$, $18.7 \%$ ). Two-drug strategies were prescribed in 927 (43.6\%) patients including mainly diuretics and RAS ( $n=327,42 \%$ of two-drug strategies). Prescriptions of three-drugs or more were used in $543(25.6 \%)$ patients. Overall, among treated patients, 1630 (76.7\%) had uncontrolled BP, of whom 462 (28.3\%) had BP levels $\geq 180 / 110 \mathrm{~mm} \mathrm{Hg}$, mainly in those on monotherapy. After adjustment for sociodemographic factors, the use of traditional medicine was the only factor significantly associated with uncontrolled BP (OR 1.72 (1.19 to 2.49) $p<0.01)$.
Strengths and limitations of this study

- Our study included over 2000 patients from 29 tertiary centres in 17 cities from 12 low and middle countries from Sub-Saharan Africa.

- Caution is needed in extrapolating the information to other population because the sampling framework in each country was not nationally representative.

- We possibly over estimated cross-sectional associations between drug regimens and blood pressure control because of other unknown cardiovascular indications.

- A multidisciplinary collaborative team of epidemiologists, cardiologists and pharmacists from Africa and France conceived and designed the study.

- Our study represents the first multination African report on antihypertensives strategies.

Conclusion Our study provided large-scale data on antihypertensive prescriptions in the African continent. Among patients declared adherent to drugs, poor BP control was significantly associated with the use of traditional medicine.

\section{INTRODUCTION}

High blood pressure (BP) is one of the leading contributors to the global burden of chronic disease, reaching 10 million deaths each year. ${ }^{1}$ In Africa, 130.2 million people suffer from hypertension and this figure is expected to reach 216.8 million by $2030 .^{2}$ Hypertension is the leading cause of cardiovascular disease (CVD) in Africa; indeed, it is a major and independent risk factor for heart failure, stroke and kidney failure. ${ }^{3}$ In SubSaharan Africa (SSA), the overall prevalence 
of hypertension is $30 \% .{ }^{4}$ In developed countries, improvements in hypertension control have led to considerable reduction in overall morbidity and mortality over the last 50 years. ${ }^{3}$ In SSA, the prevention of CVD is not always in the public health agenda. ${ }^{5}$

A combination of lifestyle modification and BP-lowering medications is the cornerstone of hypertension control. Randomised clinical trials conducted in highincome countries have shown that antihypertensive medication therapy reduces BP and cardiovascular, cerebrovascular and renal morbidity and mortality. ${ }^{6}$ Various antihypertensive drug classes including calcium channel blockers (CCB), diuretics, renin-angiotensin system (RAS) blockers, beta blockers or centrally active drug can be used alone or in combination according to international guidelines to achieve BP control. ${ }^{78}$ Although international guidelines to manage hypertension contain recommendations for black adults who live mostly in high-income countries outside of Africa, ${ }^{7} 74 \%$ of African countries have no dedicated guidelines for the management of hypertension for the predominantly black populations in these countries. ${ }^{4}$ Indeed, in SSA countries, five dimensions of access to medicine should be considered, including availability, affordability, accessibility, acceptability and quality of medicines. Among these dimensions, acceptability describes how medicines are used in real-world settings, including appropriate prescription by physicians and behaviour of patients (adherence and cultural factors). ${ }^{9}$ A few studies describe access of medication in SSA and often they examine availability and affordability of antihypertensive medicines but not the acceptability and consequences of these medications on BP control. ${ }^{10}$

There is scarce information from SSA. ${ }^{11}$ Published data are derived from worldwide studies, where SSA countries are poorly represented ${ }^{12}$ or estimated. ${ }^{13}$ Conclusions of such global studies may not always be extrapolated to these SSA countries. Furthermore, most studies in SSA are limited to single countries or centres. ${ }^{14}$

We aimed to explore acceptability by providing light on which antihypertensive drugs were prescribed by physicians and which factors were associated with the effectiveness of treatments; therefore, the purpose of the current study is to describe antihypertensive drug strategies and identify treatment factors associated with uncontrolled BP using a large multinational study conducted in 12 SSA countries: the Evaluation of Hypertension in Sub-Saharan Africa (EIGHT) study. ${ }^{15}$

\section{METHODS}

\section{Study design and setting}

We conducted an observational cross-sectional study using data collected during outpatient consultations for hypertension in cardiology departments of 29 hospitals from 17 cities across 12 SSA countries (Benin, Cameroon, Congo (Brazzaville), Democratic Republic of the Congo, Gabon, Guinea, Côte d'Ivoire, Mauritania, Mozambic, Niger,
Senegal, Togo) between January 2014 and November 2015.

A multidisciplinary collaborative team of epidemiologists, cardiologists and pharmacists from Africa and France conceived and designed The EIGHT study.

The EIGHT team had extensive prior research experience and existing collaborations with a network of physician-scientists in Africa in the field of Rheumatic heart disease ${ }^{16}$ sickle cell ${ }^{17}$ disease and quality of cardiovascular drugs,${ }^{18}$ which aided planning and launch of the present study.

This study was exclusively supported by a public grant. Due to the observational, non-interventional nature of the study, with anonymised data, written informed consent was not required whereas patient non-opposition was documented, according to legislation. After providing information regarding the study, the investigator notified patient opposition to participate in the study in the patient file.

\section{Participants}

Patients $\geq 18$ years of age with hypertension were enrolled at any visit during outpatient consultations in the cardiology departments of the participating hospitals. Each patient received an information leaflet about the study. In addition, the on-site physician presented and explained the study in the regional language to all patients' meeting eligibility criteria. Patients who agreed to participate completed a standardised questionnaire while waiting for their appointment. Participating physicians at each centre received a training note detailing the study and standardised instructions on how they should interact with the patients while completing the questionnaire.

\section{Patient and public involvement}

Patients and public were not directly involved in research design, recruitment or conduct of this study.

\section{Measurements}

A dedicated questionnaire was conceived for this study. ${ }^{15}$ A pilot investigation involving 90 patients who tested the questionnaire was conducted in January 2014 in Côte d'Ivoire.

\section{Treatment factors}

The first part of the questionnaire was completed by patients and collected data on patient sociodemographic factors (age, sex and location), site of purchase of cardiovascular drugs, use of traditional medicine and adherence to treatment. A patient was defined as non-adherent if she/he reported sometimes forgetting to take medications in his/her self questionnaire.

The second part was filled out by the physician during the consultation and collected data on socioeconomic status (patient wealth index), antihypertensive drug classes and generic prescriptions, BP values (measured in standardised conditions, see below) and cardiovascular risk factors, helping with the medical file if necessary. 
Patient wealth index was assessed by the treating physician and classified as low, middle and high:

- 'low' defined poor patients who have difficulties to afford medical consultations.

- 'Middle' defined patients who cannot systematically paying medical consultations.

- 'High' defined patients who have no difficulties to pay medical consultations.

The antihypertensive drug classes recorded were: $\mathrm{CCB}$, diuretics, RAS blockers (including angiotensinconverting enzyme inhibitors (ACEI) and angiotensin receptor blockers (ARB)), beta blockers, centrally active drugs and direct vasodilators. Antihypertensive drug strategies were defined according to the number of prescribed drug classes.

\section{BP measurement}

Seated office BP was measured two times by physicians, at least $15 \mathrm{~min}$ apart; participants were instructed to avoid caffeine and smoking within $30 \mathrm{~min}$ prior to $\mathrm{BP}$ measurement.

Uncontrolled hypertension was defined by a systolic BP $(\mathrm{SBP}) \geq 140 \mathrm{~mm} \mathrm{Hg}$ and/or a diastolic BP (DBP) of $\geq 90$ $\mathrm{mm} \mathrm{Hg}$ on either of the measured office BP values in the clinic. $^{19}$

Severity of hypertension was defined on uncontrolled BP according to European Society of Cardiology guidelines. ${ }^{19}$ Mild hypertension (SBP: $140-159 \mathrm{~mm} \mathrm{Hg}$ and/ or DBP: 90-99 $\mathrm{mm} \mathrm{Hg}$ ), moderate hypertension (SBP: 160-179 $\mathrm{mm} \mathrm{Hg}$ and/or DBP: 100-109 $\mathrm{mm} \mathrm{Hg}$ ) and severe hypertension ( $\mathrm{SBP} \geq 180 \mathrm{~mm} \mathrm{Hg}$ and/or $\mathrm{DBP} \geq 110$ $\mathrm{mm} \mathrm{Hg}$ ).

\section{Study power}

The study was designed with $90 \%$ power to detect a relative difference superior at $5 \%$ on $\mathrm{BP}$ control between monotherapy and combination therapy group of patients (with a significance level of 5\%). A total of 2060 patients were required.

\section{Statistical analysis}

Continuous and categorical variables were expressed as mean (SD) and numbers (percentage) where appropriate.

Missing data were not imputed and taken into account in descriptive data. For statistical models, only complete cases were analysed.

Categorical variables were compared using $\chi^{2}$ tests.

It is difficult to interpret the potential role of antihypertensive drugs in non-adherent patients. Therefore, the association of treatments factors with uncontrolled hypertension and hypertension severity were assessed in adherent patients only. In this way, we studied the association of treatments factors with $\mathrm{BP}$ control in patients who reported actually taking their antihypertensive drugs. The following regression models were analysed.

First, in univariate analysis, the OR and 95\% CIs of the association of treatment factors (therapeutic strategy using two-drug strategies as the reference categories, antihypertensive drugs classes, prescription of generic drugs and use of traditional medicine) with uncontrolled BP were estimated in separate logistic regression models. A random effect for country was added (generalised estimated equation models) to account for intercountry variability. Interactions between antihypertensive strategies and each antihypertensive drug class were tested as well as interaction between patient wealth index and the use of traditional medicine. Then, in a multivariate analysis, models were adjusted for sociodemographic factors along with all factors with a $p$ value of less than 0.2 in the univariate analysis.

Second, we quantified the association between treatment factors and hypertension severity using separate linear regression models with a random effect for country (generalised estimated equation models). As previously stated, all factors with a $\mathrm{p}$ value of less than 0.2 as well as sociodemographic factors were included in a model for multivariable analysis.

A two-tailed $p$ value of $<0.05$ was considered significant. All analyses were performed through scripts developed in the R software (V.3.5.1 (2 July 2018).

\section{RESULTS}

\section{Participants}

The EIGHT study included 2198 patients with hypertension in 12 SSA countries between January 2014 and November 2015. Patients' baseline data are reported in table 1 . Mean age of patients was $58.3 \pm 11.8$ years. A greater proportion of patients were women $(n=1324$, $60.2 \%)$. Overall, 1017 patients $(46.3 \%)$ were from lowincome countries (Benin, Democratic Republic of the Congo, Guinea, Mozambic, Niger and Togo) and 1181 $(53.7 \%)$ were from middle-income countries (Cameroon, Congo (Brazzaville), Gabon, Côte d'Ivoire, Mauritania, and Senegal). Most of the patients were living in urban cities $(n=1702,78.9 \%)$ compared with rural areas $(n=455$, $21.1 \%)$. Individual wealth index was low, middle and high in $376(17.6 \%), 1053(49.2 \%)$ and 713 patients $(33.3 \%)$, respectively.

\section{Treatments}

Overall, 96.6\% ( $\mathrm{n}=2123)$ of patients were prescribed antihypertensive medications (table 1). Among treated patients, $653(30.8 \%)$ patients received a monotherapy and $927(43.6 \%)$ patients received two antihypertensive drug classes (table 1). Prescriptions of three, four, five and more antihypertensive drugs were found for 425 (20.0\%), $107(4.8 \%), 11(0.4 \%)$ patients, respectively. Characteristics of patients according to therapeutic strategy are detailed in table 1.

Antihypertensive drug strategies according to country are displayed in figure 1 .

CCB $(n=1219,57.4 \%)$, diuretics $(n=1167,55.0 \%)$ and ACEI ( $\mathrm{n}=981,46.2 \%)$ were the most commonly prescribed BP-lowering drugs overall (table 1). Diuretics and renin-RAS blockers were most frequently prescribed 
Table 1 Characteristics of participants according to therapeutic strategy

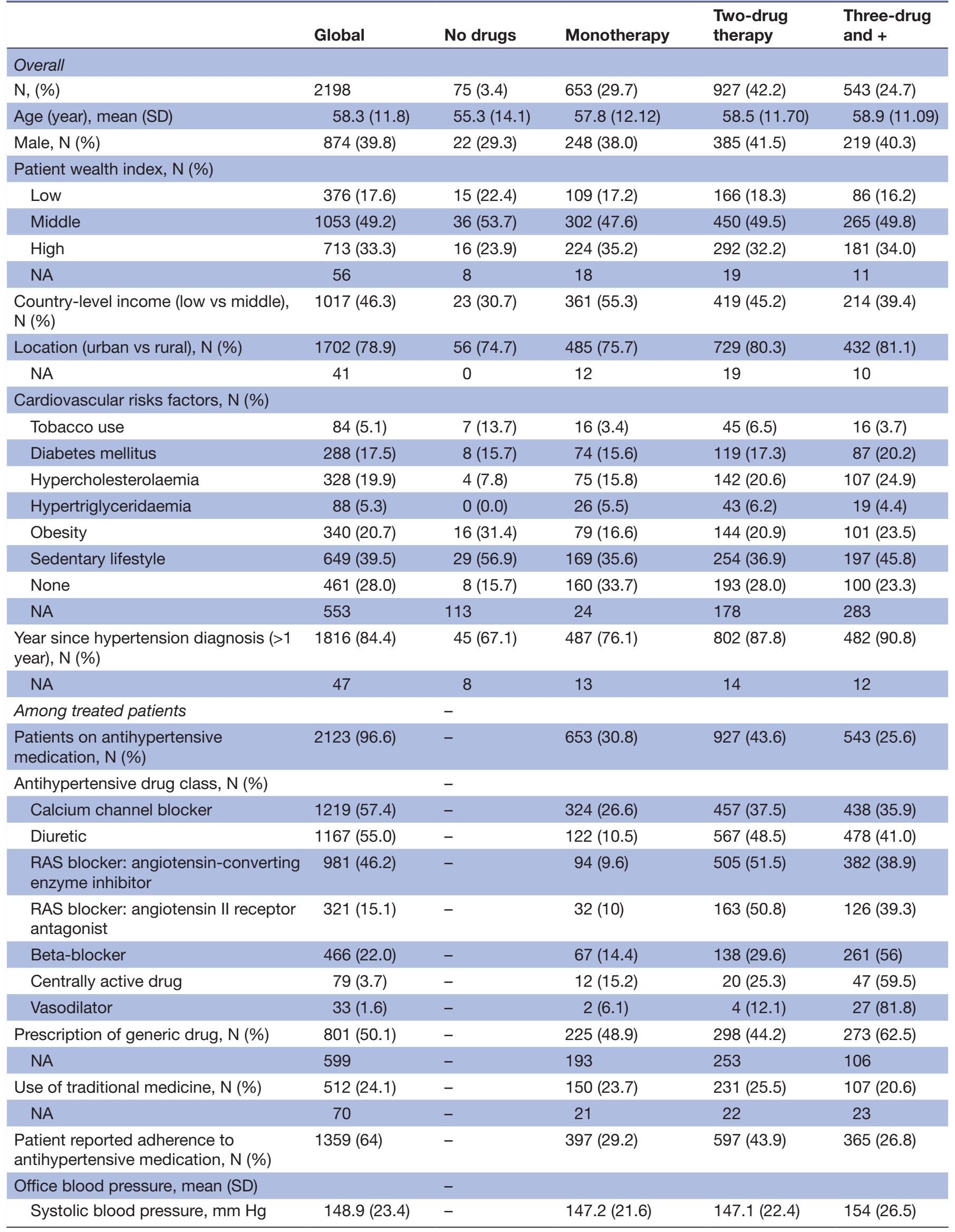


Table 1 Continued

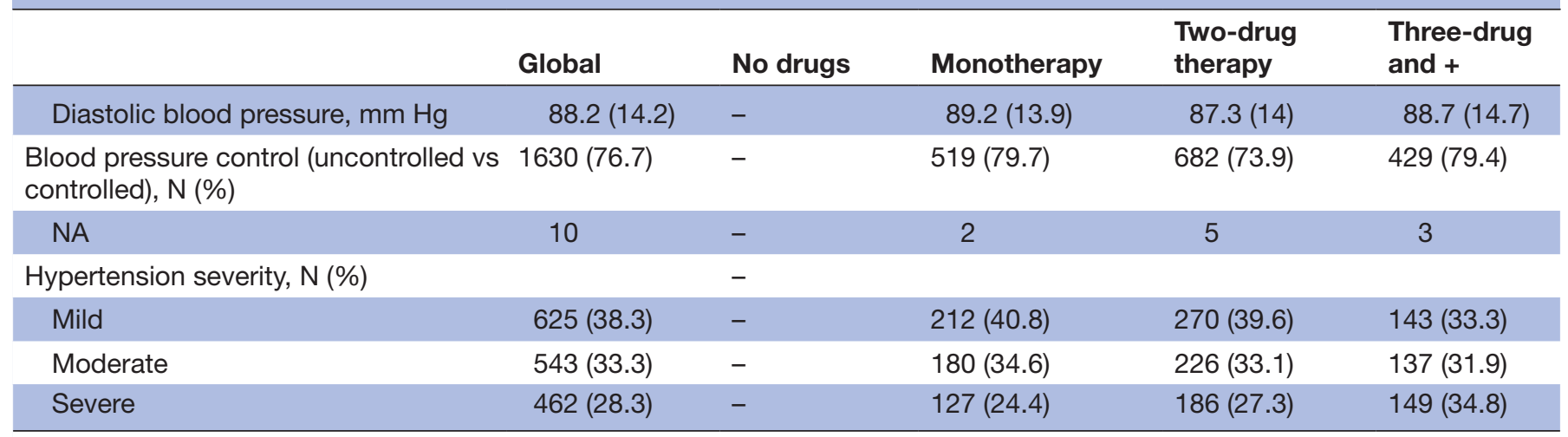

*Uncontrolled hypertension was defined by a systolic BP $\geq 140 \mathrm{~mm} \mathrm{Hg}$ and/or a diastolic BP of $\geq 90 \mathrm{~mm} \mathrm{Hg}$ on either of office BP measures in the clinic.

BP, blood pressure; RAS, renin-angiotensin system blocker.

as part of a two-drug antihypertensive medication strategy $(p<0.001)$ as compared with a one-drug or three or moredrug strategy. $\beta$-blockers were most frequently prescribed as part of a three or more drug antihypertensive medication strategy as compared with a one or two-drug strategy $(\mathrm{p}<0.001)$.

Antihypertensive drugs according to medication strategies are presented in online supplemental table 1. CCB were the most widely prescribed monotherapy $(n=324$, $49.6 \%)$ followed by RAS blockers ( $\mathrm{n}=126,19.3 \%)$, diuretics $(\mathrm{n}=122,18.7 \%)$ and $\beta$-blockers $(\mathrm{n}=67,10.3 \%)$. The three most common two-drug strategies were composed of diuretics+RAS blockers and CCBs+RAS blockers. Among three-drug strategies, the three most common strategies $(\mathrm{CCB}+$ diuretics + RAS blockers; diuretics $+\beta$ blockers $+\mathrm{RAS}$ blockers; $\mathrm{CCB}+\beta$ blockers+RAS blockers) represented $84.5 \%$ of prescriptions. The triple prescription strategies of diuretics+CCB+RAS blockers represented almost half of the three-drug strategy prescriptions $(n=250,54.1 \%)$.
Among four-drug strategies, the most common prescription strategy of $\mathrm{CCB}+$ diuretics $+\beta$ blockers + RAS blockers constituted $73.8 \%(\mathrm{n}=79)$ of prescriptions.

About half of patients were prescribed at least one generic drug ( $\mathrm{n}=801,50 \%)$ (table 1$)$.

Among patients prescribed antihypertensive medication, $64 \%$ reported adherence to treatment.

A quarter $(n=512,24.1 \%)$ of patients used traditional medicine in addition to other drugs, and this proportion was similar whatever the pharmacological antihypertensive drug strategy prescribed (monotherapy, two-drug strategies, three-drug strategies and more; $\mathrm{p}=0.107$ ). The percentage of patients using traditional medicine varied from $9.9 \%(17 / 178)$ in Congo to $47.7 \%(82 / 172)$ in Guinea.

Factors associated with uncontrolled hypertension Overall, $1630(76.7 \%)$ had uncontrolled BP. BP control according to countries was depicted in online

\begin{tabular}{|c|c|c|c|c|}
\hline Income level/Countries & $\mathbf{N}$ & Monotherapy & Two-drug & Three-drug and more \\
\hline \multirow[t]{5}{*}{ Low income } & Togo, 246 (\%) & & & \\
\hline & Benin, 104 (\%) & & & \\
\hline & Niger, 71 (\%) & & & \\
\hline & tambic, 148 (\%) & & & \\
\hline & Suinea, 170 (\%) & & & \\
\hline \multicolumn{5}{|c|}{ Democratic republic of the Congo, $255(\%)$} \\
\hline \multirow[t]{6}{*}{ Middle income } & Congo, 177 (\%) & & & \\
\hline & 'Ivoire, 292 (\%) & & & \\
\hline & uritania, 84 (\%) & & & \\
\hline & enegal, 142 (\%) & $\square$ & & \\
\hline & eroon, 354 (\%) & $\square$ & & \\
\hline & Gabon, 80 (\%) & $0 \%$ & & \\
\hline
\end{tabular}

Figure 1 Antihypertensive drugs strategies (\%) according to countries level income and countries. Bars represent the percentage of antihypertensive drugs strategies. 


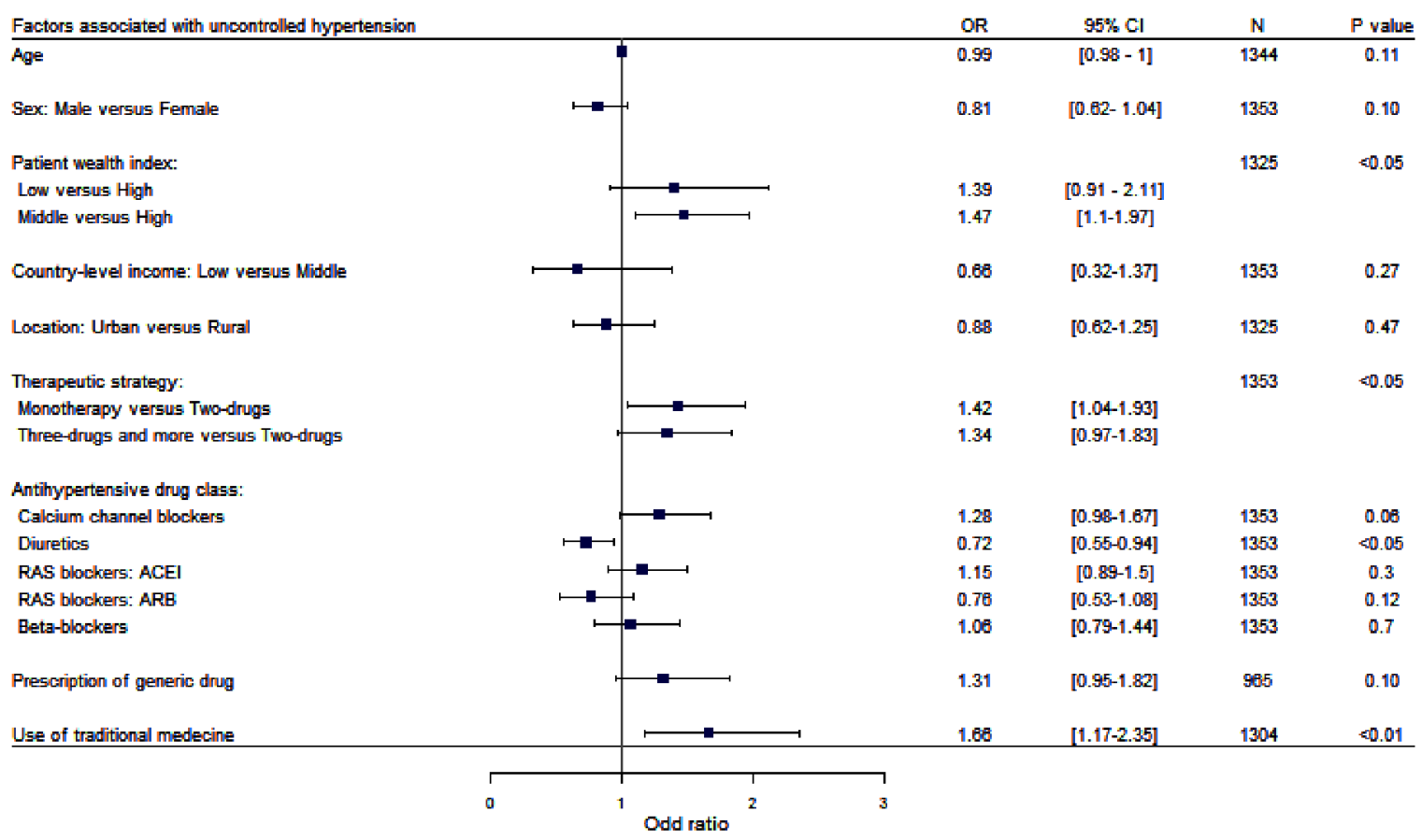

Figure 2 OR of sociodemographic and treatments factors for uncontrolled hypertension among patients who declared to be adherent to medications in univariate analysis. Squares represent OR and lines, $95 \% \mathrm{Cl}$. ORs derived from separated logistic regression with a random effect on country to account for inter-country variability. $\mathrm{N}$ represents overall for each variable. ACEI, angiotensin-converting enzyme inhibitors; ARB, angiotensin receptor blockers; RAS, renin-angiotensin system.

supplemental table 2. Drug strategies by BP control are described in table 1 . In univariate analysis, among patients who reported adherence to antihypertensive medication, factors associated with uncontrolled BP are detailed in figure 2. The proportion of patients with uncontrolled BP was significantly increased with individual wealth index (middle vs high as reference), with monotherapy (vs two-drug therapy as reference) and with the use of traditional medicine $(\mathrm{p}<0.05)$. Patients treated with diuretics (vs patients without diuretics) had more frequently controlled BP (OR 0.72 (0.55 to 0.94$) \mathrm{p}<0.05$ ); this association was not found for any other class of antihypertensive drugs.

In multivariable analysis among adherent patients adjusted for sociodemographic factors (age, sex, individual wealth index and location (rural or urban)), the use of traditional medicine remained the only factor significantly associated with uncontrolled hypertension (OR 1.72 (1.19 to 2.49), $\mathrm{p}<0.01$ ) (figure 3 ). None of the antihypertensive drugs classes alone was associated with uncontrolled hypertension. There was no significant interaction between antihypertensive drug strategy and class and between patient wealth index and the use of traditional medicine.

\section{Factors associated with severity of hypertension}

Drug strategies are described by hypertension severity in table 1. Among patients with severe hypertension, $127(27.5 \%)$ were treated with a monotherapy. This proportion varied across countries (figure 4). In univariate analysis, among adherent patients, the proportion of patients with severe hypertension was higher in patients with three-drug and more strategies (vs two-drug therapy), and with $\mathrm{CCB}$, diuretics and the use traditional medicine $(\mathrm{p}<0.05)$ (online supplemental table 1).

In multivariable analysis, among adherent patients adjusted for sociodemographic factors, the use of traditional medicine remained associated with higher grades of hypertension (linear regression coefficient $=0.15$; (0.029 to 0.28$), \mathrm{p}<0.05)$.

\section{DISCUSSION}

\section{Key results}

Overall, 653 (30.8\%) patients received antihypertensive medication monotherapy, $927(43.6 \%)$ received two-drug strategies and $543(25.6 \%)$ received three drugs and more. These proportions varied across countries.

$\mathrm{CCB}$ was the most common antihypertensive drug class prescribed among all strategies. However, if ACEI and ARB were considered as one antihypertensive drug class merged into RAS blockers, they represented $68 \%$ of all prescriptions.

We found that the use of traditional medicine was an important determinant of poor BP control, beyond the traditional factors including patient wealth index and 


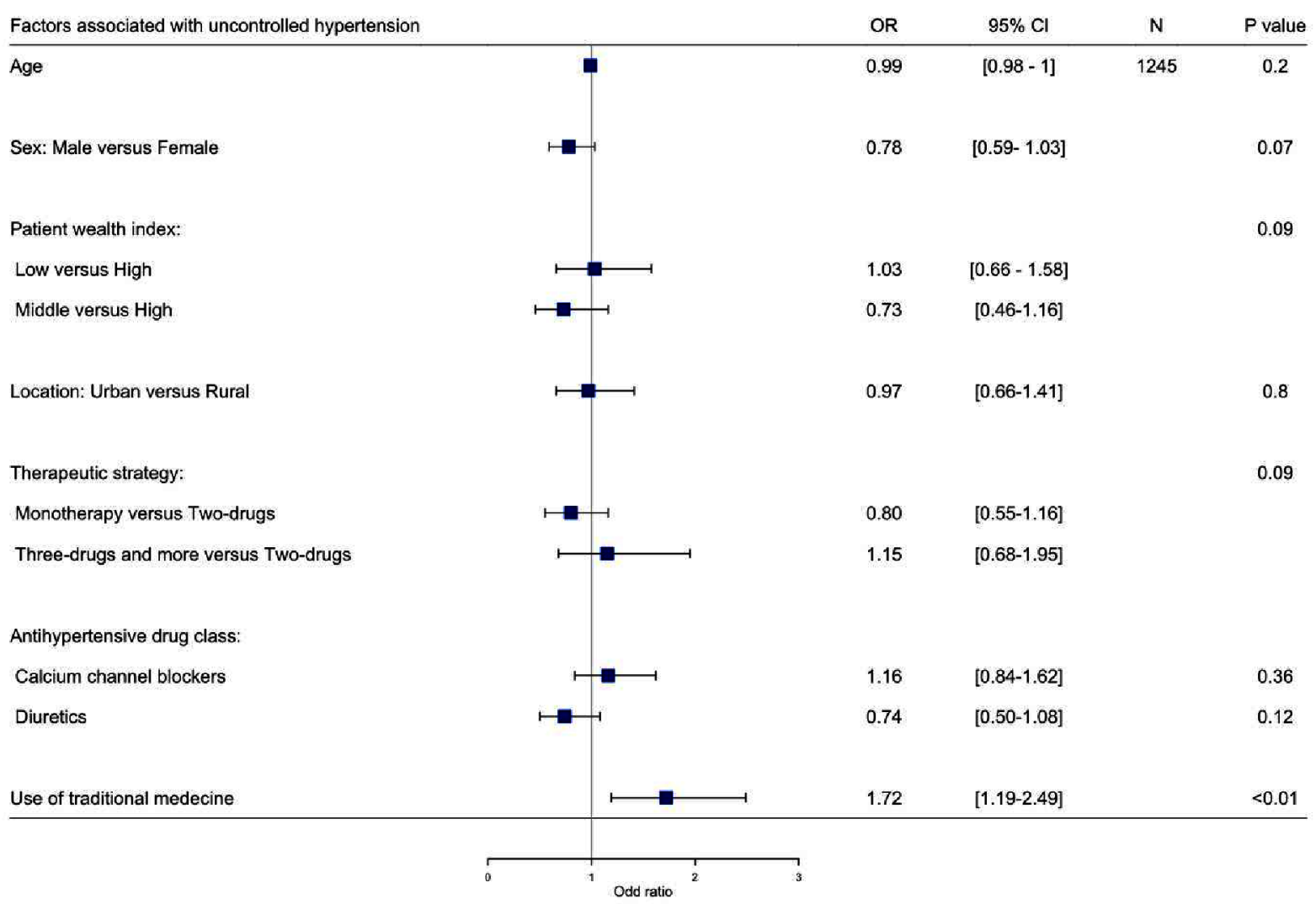

Figure 3 OR of treatments factors for uncontrolled hypertension among patients who declared to be adherent to medications adjusted for sociodemographic factors in multivariate analysis. Squares represent OR and lines, $95 \% \mathrm{Cl}$. ORs derived from separated logistic regression with a random effect on country to account for inter-country variability. $\mathrm{N}$ represents overall for each variable. ACEI, angiotensin-converting enzyme inhibitors; ARB, angiotensin receptor blockers; RAS, renin-angiotensin system.

adherence to medication. Medical staff attention should particularly be provided to these patients.

\section{Antihypertensive drug strategies}

The proportion of patients on antihypertensive medications in our study was very high. This is related to the recruitment of patients during outpatient consultations in cardiology departments or urban hospitals. There is scarce data on proportion of patients treated with antihypertensive medication among patients aware of a hypertension diagnosis in SSA. According to the Eighth Joint National Committee, the first recommended line of treatment for black hypertensive patients is diuretics or CCB alone or in combination..$^{20}$ Accordingly, CCBs alone or in combination were widely prescribed in our study. Surprisingly, RAS blockers and especially ACEI were the second most prescribed treatment alone before diuretics even though these are less effective compared with CCBs in reducing $\mathrm{BP}$ in black hypertensive patients. ${ }^{21}$ Physicians in the EIGHT study seem to follow international guidelines for black patients regarding CCB prescriptions. The high proportion of ACEI prescriptions (usually not recommended for black patients except for compelling indications including heart failure, postmyocardial infarction, diabetes, proteinuric nephropathy) suggests that continuing education of physician could be an avenue for improved care. Though, our methodology did not allow to completely distinguish indications of some drugs, and particularly to know whether ACEI were prescribed in a compelling indication because of the non-reported patient's comorbidities. Diuretics should be considered, particularly due to their low cost. ${ }^{22}$

Even among patients recruited from tertiary cardiology centres in urban areas in Sub-Saharan countries, BP control remains very poor and monotherapy remains widely prescribed. Some barriers associated with uptitration of treatments could be cited. Access to medicines, defined by availability, affordability, accessibility, quality and acceptability of antihypertensive drugs varied across low and middle-income countries. These factors are associated with poor BP control. ${ }^{9} 2324$

In low and middle-income countries, a large proportion of communities does not have access to more than one antihypertensive drug and, when available, they are often not affordable. In a multinational study among 68 950 households, the proportion of households unable to afford two BP-lowering medicines was $31 \%$ in low-income countries and $9 \%$ in middle-income countries. ${ }^{11}$ Furthermore, we cannot exclude that the pharmaceutical quality 


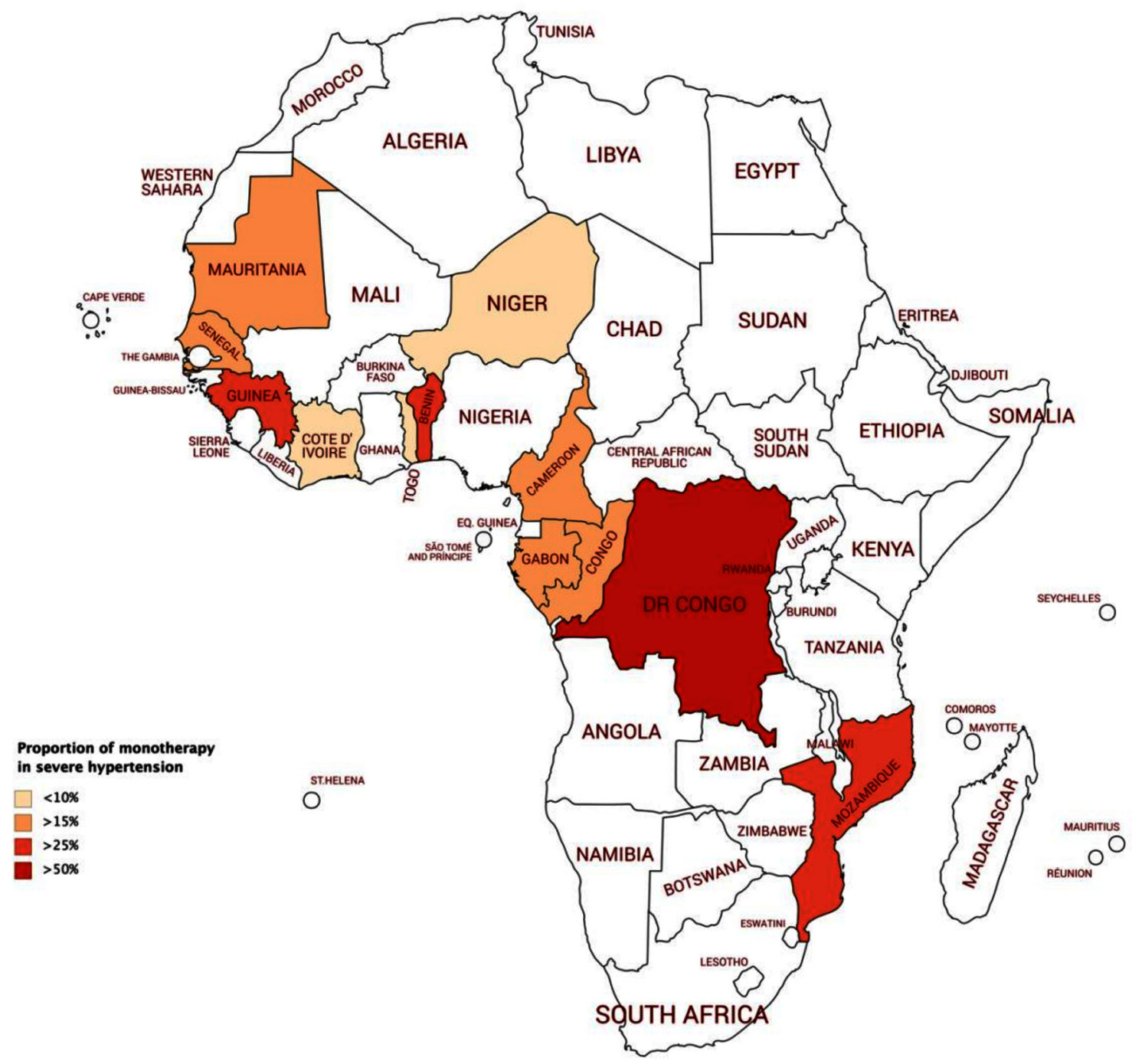

Figure 4 Proportion of monotherapy in patients with severe hypertension. Grey countries were not included in the Evaluation of Hypertension in Sub-Saharan Africa study.

of drugs did not contribute to treatment failure. Indeed, we have previously shown in the SEVEN study that $16 \%$ of cardiovascular drugs have poor quality in SSA, especially $\mathrm{CCB}$, and the proportion of poor quality can reach $50 \%$ when drugs produced in Asia are sold in street markets. ${ }^{18}$

Among solutions, fixed drug combinations have been shown to enhance adherence and effectiveness of treatment by combining different treatments with different mechanisms of action. Randomised controlled trial on adherence to treatment by providing fixed drug combination free of charge in other part of the world achieve to increase BP control. ${ }^{25}$ However, fixed drug combinations are poorly available and affordable in low and middleincome countries. Nevertheless, using fixed drug combinations had limitations: they may have potentially higher prices versus the cost of the components combined, they may be only available as 'branded' medicines in some countries and consequently only available in private pharmacies rather than public facilities and not in rural area. ${ }^{26}$

\section{Traditional medicine}

Our results underlined the strong association between the use of traditional medicine and uncontrolled BP, after adjusting for well-known factors associated with poor BP control including age, sex, socioeconomic factors and poor adherence to treatment. ${ }^{27}$ The WHO define the use of traditional medicine as the sum total of the knowledge, skill and practices based on the theories, beliefs and experiences indigenous to different cultures, whether explicable or not, used in the maintenance of health as well as in the prevention, diagnosis, improvement or treatment of physical and mental illness. ${ }^{28}$ The prevalence of the use of traditional medicine is rising worldwide and is well documented in both African countries and worldwide to be between $20 \%$ and $80 \% .{ }^{29}{ }^{30}$ We found that $24.1 \%$ of patients (range $9.9 \%-47.7 \%$ ) used traditional medicine, consistent with the literature. ${ }^{31}$ Several factors have previously been reported to be associated with the use of traditional medicine, including 
sociodemographic characteristics of patients, dissatisfaction with conventional treatments (ineffective treatments or side effects), cultural beliefs that illnesses have a 'spiritual' origin, availability and affordability of antihypertensive drugs. ${ }^{31}$ In our study, conventional medicine and traditional medicine were concurrently used. Studies have shown that patients used traditional medicine along with their conventional treatments, ${ }^{32}$ but use of traditional medicine was strongly associated with poor adherence to conventional treatments. ${ }^{27}$ Our study methodology does not allow us to describe more specifically patients' behaviour towards traditional medicine. The reasons why patients choose to use traditional medicine have been much discussed but not fully understood. ${ }^{33} 34$ They may lose trust confidence in conventional medicine. In our study, patients declared to use traditional medicine, unfortunately details of traditional medicine were not depicted (herbal medicines, indigenous healthcare practices, complementary and complementary medicine like acupuncture or chiropractic, consultation of traditional health practitioners). Use of natural medicines is one kind of Traditional medicine. Systematic review on traditional herbal medicine use among hypertensive patients in SSA has been published ${ }^{35}$ and they find a list of more than 20 different herbals used in different forms (extract that needed to be dissolved, steam inhalation, single herbs and mixtures herbs). We cannot exclude that this preparation of natural medicine could increase BP. In SSA, traditional health practitioner and physicians are cohabiting. To the burden of high BP, they should work together to improve BP control. Interventional models of care to fight hypertension are currently being developed, and for us, traditional medicine should be integrated as a part of hypertension management. In a previous analysis of the EIGHT study, the use of traditional medicine was shown to be strongly associated with poor adherence to conventional treatments. ${ }^{27}$ It would be an interesting and useful addition to include traditional medicine and traditional health practitioners in interventional model of care. ${ }^{3637}$

\section{Limitation and strength}

We acknowledged the following limitations. Caution is needed in extrapolating the information in the current study to other population because the sampling framework in each country was not nationally representative. The data in the EIGHT study were derived from urban clinics and likely represents the best-case scenario for BP treatment and control. Therefore, the magnitude of uncontrolled BP in the general population with hypertension could be underestimated. Although a random selection of centres would be ideal from a methodological perspective, such an approach is not practical given the lack of cardiovascular care in this part of the world. The 6-7-year gap between data collection and reporting is not significant in terms of antihypertensive drugs, for which there have been no significant innovations in the last 6 years. Traditional medicine is ancestral and changes in physicians' practices as well as in antihypertensive medication strategies are elements that evolve slowly. We can fear to overestimate BP figures and, therefore, uncontrolled hypertension because of the white coat effect during one visit. We tried to consider this effect by measuring seated office BP two times by physicians. We chose this measure because it was appropriate for the African setting. Defining uncontrolled hypertension versus controlled hypertension based on office $\mathrm{BP}$ readings during one visit was open to criticism, but we cannot be sure that patients will ever come back in outpatient consultation. Concerning antihypertensive drug classes, aldosterone antagonist and thiazide diuretic were not differentiated in our study. For antihypertensive drug strategies, even if a patient has a prescription for single-pill combination, they may be unable to purchase this treatment. We, therefore, decided not to incorporate this information in our analysis. We probably over estimated cross-sectional associations between drug regimens and BP control because of other unknown cardiovascular indications. Furthermore, this study could not take into account the role of indication bias in interpreting cross-sectional associations between drug regimens and BP control. We could fear to overestimate adherence because of using self-reported questionnaire. However, self-reported medication adherence is a practical way to measure adherence because of its low cost and potential to be easily implemented into the clinical workflow. Also, evidence pointed out that selfreported adherence is predictive of clinical outcomes and especially in hypertension. ${ }^{38} 39$

This study had many strengths, including its multisite design, with over 2000 patients from 29 medical centres in 17 cities from 12 countries. Actual data on management of CVD are uncommon in Africa and are usually derived from small, single-centre studies. The EIGHT study embraced 12 African countries, which are usually not considered in international studies, such as the PURE study (The Prospective Urban Rural Epidemiology study), ${ }^{11}$ providing global data on cardiovascular epidemiology. Furthermore, this study was supported by a strong and structured collaborative multidisciplinary network. Active involvement of African cardiologists, who are familiar with the problems of this area, helped derivespecific questions and analysis.

\section{CONCLUSION}

Hypertension is a rapidly growing epidemic in low and middle-income countries. In this multinational study, we described antihypertensive drugs by classes in SubSaharan Africa. Our study provided large-scale data on antihypertensive prescriptions in the African continent. Among patients declared adherent to drugs, poor BP control was significantly associated with the use of traditional medicine.

Author affiliations

${ }^{1}$ Department of Pharmacy, St Antoine Hospital, AP-HP Sorbonne Université, Paris, France 
${ }^{2}$ Université de Paris, PARCC, INSERM, F-75015 Paris, France, Paris, France ${ }^{3}$ Department of Internal Medicine, General Hospital of Kinshasa, Kinshasa, Democratic Republic of the Congo

${ }^{4}$ Cardiology, Central Hospital of Lome, Lome, Togo

${ }^{5}$ Internal Medicine, Regional Hospital, Bafoussam, Cameroon

${ }^{6}$ Cardiology, University Hospital of Fann, Dakar, Senegal

${ }^{7}$ Cardiology, National University Hospital of Brazzaville, Marien NGOUABI University, Brazzaville, Congo

${ }^{8}$ Cardiology, Institute of Cardiology of Abidjan (Côte d'Ivoire), BPV 206, abidjan, Côte d'Ivoire

${ }^{9}$ Internal Medicine and Cardiology, University Hospital of Lamorde, Niamey University, Niamey, Niger

${ }^{10}$ Cardiology, University Hospital of Conakry, Conakry, Guinea

${ }^{11}$ Cardiac Intensive Care \& Cardiac Pacing Unit, Douala General Hospital, Douala,

Cameroon

${ }^{12}$ Instituto do Coração, Maputo, Mozambique

${ }^{13}$ National University Hospital of Hubert K. MAGA (CNHU-HKM), Cotonou, Benin

${ }^{14}$ Cardiology, St Louis Hospital, Dakar, Senegal

${ }^{15}$ University of Yaoundé, Ministry of Public Health, Yaoundé, Cameroon

${ }^{16}$ Cardiology, University of Medicine of Kinshasa, Kinshasa, Democratic Republic of the Congo

${ }^{17}$ Department of Internal Medicine of la Gombe (CMCG), Department of Internal

Medicine, Ngaliema Hospital, Kinshasa, Democratic Republic of the Congo

${ }^{18}$ Cardiology, Central hospital of Yaoundé, Yaoundé, Cameroon

${ }^{19}$ Cardiology, University Hospital of Libreville, Libreville, Gabon

${ }^{20}$ Cardiology clinics, Nouakchott, Mauritania

${ }^{21}$ Department of Health Services Administration Cardiology Clinics and Policy,

Temple University, Philadelphia, Pennsylvania, USA

${ }^{22}$ Hypertension Unit, European Georges Pompidou Hospital, AP-HP Centre, Paris, France

${ }^{23}$ INSERM, Centre d'Investigation Clinique 1418, Paris, France

${ }^{24}$ Cardiovascular epidemiology department, University of Paris, Paris, France

${ }^{25}$ Cardiology, European Georges Pompidou Hospital, AP-HP Centre, Paris, France

Contributors All authors have substantial contributions. MA is responsible for the overall content as the gaurantor. PC, MA and XJ had full access to the whole data in the study and take responsibility for integrity of the data and accuracy of data analysis. Those authors take responsibility for all aspects of the reliability and freedom from bias of the data presented and their discussed interpretation. Study concept and design: MA, IBD XJ. Responsible for data collection : IBD, KEK, IAT, DB, BF, MH, SI, AK, SGK-k, SK, CKK, LMK, CN, EL, JLT, JBM, ASA, RN'G, AD, JMD. Interpretation of data: all authors. Statistical analysis: PC, MA, MCP, XJ. Drafting of the manuscript: PC, MA, MA, XJ. Critical revision of the manuscript for important intellectual content: PC, MA, MA, GST, DMDT, BG, XJ. Final approval of the version to be published: all authors

Funding The study was exclusively supported by a public grant: INSERM (Institut national de la Santé et de la Recherche Médicale), AP-HP (Assistance PubliqueHôpitaux de Paris), Paris Descartes University.

Map disclaimer The inclusion of any map (including the depiction of any boundaries therein), or of any geographic or locational reference, does not imply the expression of any opinion whatsoever on the part of BMJ concerning the legal status of any country, territory, jurisdiction or area or of its authorities. Any such expression remains solely that of the relevant source and is not endorsed by BMJ. Maps are provided without any warranty of any kind, either express or implied.

Competing interests None declared.

Patient consent for publication Not applicable.

Ethics approval The study was approved by the Ile-de-France III ethics committee (Number 2014-A00710-47) and was declared to the National Commission of Informatics (Number 1762715).

Provenance and peer review Not commissioned; externally peer reviewed.

Data availability statement Data are available upon reasonable request. PC, MA and XJ had full access to the whole data in the study and take responsibility for integrity of the data and accuracy of data analysis. All data are available on request.

Supplemental material This content has been supplied by the author(s). It has not been vetted by BMJ Publishing Group Limited (BMJ) and may not have been peer-reviewed. Any opinions or recommendations discussed are solely those of the author(s) and are not endorsed by BMJ. BMJ disclaims all liability and responsibility arising from any reliance placed on the content. Where the content includes any translated material, BMJ does not warrant the accuracy and reliability of the translations (including but not limited to local regulations, clinical guidelines, terminology, drug names and drug dosages), and is not responsible for any error and/or omissions arising from translation and adaptation or otherwise.

Open access This is an open access article distributed in accordance with the Creative Commons Attribution Non Commercial (CC BY-NC 4.0) license, which permits others to distribute, remix, adapt, build upon this work non-commercially, and license their derivative works on different terms, provided the original work is properly cited, appropriate credit is given, any changes made indicated, and the use is non-commercial. See: http://creativecommons.org/licenses/by-nc/4.0/.

\section{ORCID iDs}

Pauline Cavagna http://orcid.org/0000-0002-2749-8836

Anastase Dzudie http://orcid.org/0000-0003-4038-4128

Bamba Gaye http://orcid.org/0000-0002-5516-4665

\section{REFERENCES}

1 GBD 2017 Risk Factor Collaborators. Global, regional, and nationa comparative risk assessment of 84 behavioural, environmental and occupational, and metabolic risks or clusters of risks for 195 countries and territories, 1990-2017: a systematic analysis for the global burden of disease study 2017. Lancet 2018;392:1923-94.

2 Adeloye D, Basquill C. Estimating the prevalence and awareness rates of hypertension in Africa: a systematic analysis. PLoS One 2014:9:e104300.

3 Kayima J, Wanyenze RK, Katamba A, et al. Hypertension awareness, treatment and control in Africa: a systematic review. BMC Cardiovasc Disord 2013;13:54. doi:10.1186/1471-2261-13-54

4 Kuate Defo B, Mbanya JC, Kingue S, et al. Blood pressure and burden of hypertension in Cameroon, a microcosm of Africa: a systematic review and meta-analysis of population-based studies. J Hypertens 2019;37:2190-9.

5 Twagirumukiza M, De Bacquer D, Kips JG, et al. Current and projected prevalence of arterial hypertension in sub-Saharan Africa by sex, age and habitat: an estimate from population studies. $J$ Hypertens 2011:29:1243-52.

6 Mills KT, Obst KM, Shen W, et al. Comparative effectiveness of implementation strategies for blood pressure control in hypertensive patients: a systematic review and meta-analysis. Ann Intern Med 2018;168:110-20.

7 Williams B, Mancia G, Spiering W, et al. 2018 ESC/ESH guidelines for the management of arterial hypertension. Eur Heart $J$ 2018;39:3021-104.

8 Whelton PK, Carey RM, Aronow WS, et al. 2017 ACC/AHA/AAPA ABC/ACPM/AGS/APhA/ASH/ASPC/NMA/PCNA guideline for the prevention, detection, evaluation, and management of high blood pressure in adults: a report of the American College of Cardiology/ American heart association Task force on clinical practice guidelines. Hypertension 2018;71:e13-115.

9 Wirtz VJ, Kaplan WA, Kwan GF, et al. Access to medications for cardiovascular diseases in low- and middle-income countries. Circulation 2016;133:2076-85.

10 Antignac M, Marijon E, Jouven X. Letter by Antignac et al regarding article "access to medications for cardiovascular diseases in lowand middle-income countries". Circulation 2016;134:e303-4.

11 Attaei MW, Khatib R, McKee M, et al. Availability and affordability of blood pressure-lowering medicines and the effect on blood pressure control in high-income, middle-income, and low-income countries: an analysis of the pure study data. Lancet Public Health 2017;2:e411-9.

12 Roth GA, Nguyen G, Forouzanfar MH, et al. Estimates of global and regional premature cardiovascular mortality in 2025. Circulation 2015;132:1270-82

13 Chow CK, Teo KK, Rangarajan S, et al. Prevalence, awareness, treatment, and control of hypertension in rural and urban communities in high-, middle-, and low-income countries. JAMA 2013;310:959-68.

14 Mutua EM, Gitonga MM, Mbuthia B, et al. Level of blood pressure control among hypertensive patients on follow-up in a regional referral hospital in central Kenya. Pan Afr Med J 2014;18:278.

15 Antignac M, Diop IB, Macquart de Terline D, et al. Socioeconomic status and hypertension control in sub-Saharan Africa: the multination eight study (evaluation of hypertension in sub-Saharan Africa). Hypertension 2018;71:577-84. 
16 Marijon E, Ou P, Celermajer DS, et al. Prevalence of rheumatic heart disease detected by echocardiographic screening. $N$ Engl J Med 2007;357:470-6.

17 Ranque B, Menet A, Diop IB, et al. Early renal damage in patients with sickle cell disease in sub-Saharan Africa: a multinational, prospective, cross-sectional study. Lancet Haematol 2014;1:e64-73.

18 Antignac M, Diop BI, Macquart de Terline D, et al. Fighting fake medicines: first quality evaluation of cardiac drugs in Africa. Int $J$ Cardiol 2017;243:523-8.

19 ESH/ESC Task Force for the Management of Arterial Hypertension. 2013 practice guidelines for the management of arterial hypertension of the European Society of hypertension (ESH) and the European Society of cardiology (ESC): ESH/ESC Task force for the management of arterial hypertension. J Hypertens 2013;31:1925-38.

20 James PA, Oparil S, Carter BL. 2014 evidence-based guideline for the management of high blood pressure in adults: report from the panel members appointed to the eighth joint National Committee (JNC 8). JAMA 20142014;311:507-20.

21 Leenen FHH, Nwachuku CE, Black HR, et al. Clinical events in highrisk hypertensive patients randomly assigned to calcium channel blocker versus angiotensin-converting enzyme inhibitor in the antihypertensive and lipid-lowering treatment to prevent heart attack trial. Hypertension 2006;48:374-84.

22 Kramoh KE, Aké-Traboulsi E, Konin C, et al. Management of hypertension in the elderly patient at Abidjan cardiology Institute (Ivory Coast). Int J Hypertens 2012;2012:1-6.

23 Ashigbie PG, Rockers PC, Laing RO, et al. Availability and prices of medicines for non-communicable diseases at health facilities and retail drug outlets in Kenya: a cross-sectional survey in eight counties. BMJ Open 2020;10:e035132.

24 Kaiser AH, Hehman L, Forsberg BC, et al. Availability, prices and affordability of essential medicines for treatment of diabetes and hypertension in private pharmacies in Zambia. PLoS One 2019;14:e0226169.

25 Persaud N, Bedard M, Boozary AS. Effect on treatment adherence of distributing essential medicines at no charge: the clean Meds randomized clinical trial. JAMA Intern Med 2020;180:27-34.

26 Godman B, McCabe H, D Leong T. Fixed dose drug combinations - are they pharmacoeconomically sound? findings and implications especially for lower- and middle-income countries. Expert Rev Pharmacoecon Outcomes Res 2020;20:1-26.
27 Macquart de Terline D, Kane A, Kramoh KE, et al. Factors associated with poor adherence to medication among hypertensive patients in twelve low and middle income sub-Saharan countries. PLoS One 2019;14:e0219266.

28 World Health Organization. WHO traditional medicine strategy. 20142023. Geneva: World Health Organization, 2013: 76.

29 Eisenberg DM, Davis RB, Ettner SL, et al. Trends in alternative medicine use in the United States, 1990-1997: results of a follow-up national survey. JAMA 1998;280:1569-75.

30 Eddouks M, Maghrani M, Lemhadri A, et al. Ethnopharmacological survey of medicinal plants used for the treatment of diabetes mellitus, hypertension and cardiac diseases in the south-east region of Morocco (Tafilalet). J Ethnopharmacol 2002;82:97-103.

31 Osamor PE, Owumi BE. Complementary and alternative medicine in the management of hypertension in an urban Nigerian community. BMC Complement Altern Med 2010;10:36.

32 Nuwaha F, Musinguzi G. Use of alternative medicine for hypertension in Buikwe and Mukono districts of Uganda: a cross sectional study. BMC Complement Altern Med 2013;13:301.

33 Lorenc A, llan-Clarke Y, Robinson N, et al. How parents choose to use cam: a systematic review of theoretical models. BMC Complement Altern Med 2009;9:9.

34 James PB, Wardle J, Steel A, et al. Traditional, complementary and alternative medicine use in sub-Saharan Africa: a systematic review. BMJ Glob Health 2018;3:e000895.

35 Liwa A, Roediger R, Jaka $\mathrm{H}$, et al. Herbal and alternative medicine use in Tanzanian adults admitted with Hypertension-Related diseases: a mixed-methods study. Int J Hypertens 2017;2017:1-9.

36 Krah E, de Kruijf J, Ragno L. Integrating traditional healers into the health care system: challenges and opportunities in rural Northern Ghana. J Community Health 2018;43:157-63.

37 Cavagna P, Kramoh KE, Sidy Ali A, et al. The importance of considering cultural and environmental elements in an interventional model of care to fight hypertension in Africa. $J$ Clin Hypertens 2021;23:1269-70.

38 Chowdhury R, Khan H, Heydon E, et al. Adherence to cardiovascular therapy: a meta-analysis of prevalence and clinical consequences. Eur Heart J 2013;34:2940-8.

39 Korb-Savoldelli V, Gillaizeau F, Pouchot J, et al. Validation of a French version of the 8-item morisky medication adherence scale in hypertensive adults. J Clin Hypertens 2012;14:429-34. 